\title{
Television Product Placement Strategy in Thailand and the UK
}

\author{
Amy Rungpaka Hackley \\ Queen Mary, University of London \\ Chris Hackley \\ Royal Holloway University of London
}

\begin{abstract}
This paper discusses the implications for international brand communications management of a qualitative cross-national research study on television product placement in the United Kingdom and Thailand. The study involved secondary research into the respective media environments and depth interviews with leading agency practitioners in each country. The research suggests that, while television product placement practice may be superficially similar in Asia and the UK, there are important differences arising from the very different regulatory, media and consumer environments. As a consequence, detailed local knowledge is essential for successful product placement strategy which crosses cultural borders. The paper explains key differences in regulation and practice and explores implications for brand communications practice and research.
\end{abstract}

Keywords: Television product placement, Asia, UK

\section{Introduction}

Product placement, also sometimes known as brand placement or entertainment marketing (Hudson and Hudson, 2006: Lehu, 2007) has been a tool of marketing communications for more than 100 years (van Reijmersdal et al 2010) and a topic of academic research for almost 30 years (Karrh et al, 2003). Worldwide promotional spend on brand placement has been on an upward trajectory, standing at an estimated at US\$4.4 billion in 2007 (Smit et al, 2009). In spite of this level of interest, there is still relatively little academic research into best practice which focuses on television product placement, especially in cross-cultural contexts where brands are seeking exposure across national boundaries. Placements are common in syndicated (usually US) TV shows which air in different countries, but are expensive to procure and are culturally located in the country of origin. Alternatively, placements in locally produced programming offer a relatively low-cost route to prime time television exposure, within a localized cultural context. However, the different media environments, consumer cultures and regulations in Asia and the West present major problems for brand owners seeking to manage television product placement as an aspect of their international brand communications strategy. This paper seeks to engage with this research gap by exploring expert practitioners' views in two countries which offer some enlightening contrasts of practice and environment; Thailand and the UK. 
Paid-for product placement is common practice in Thailand and has been so for some time. In the UK, paid-for product placement was first permitted under new regulations in 2011, but the new paid-for market has seen slow growth (Hackley and Hackley, in press). However, it is common to see brands on UK TV through the 'free prop supply' system (Tiwsakul and Hackley, 2009), explained later in the paper. In both countries, TV viewership is high and the respective marketing communication industries are well-developed. There is increasing awareness of Thai products in the UK and many UK brands carry great prestige in Thailand, yet there are relatively few published studies of television product placement practice in either country. This paper outlines previous research in the field before exploring the respective media environments in each country. It then discusses some of the key findings from leading practitioners interviewed in Bangkok and London. Finally, common practices and differences are discussed.

\section{Product Placement Research}

Research and practitioner interest in product placement has grown (Reijmersdal et al, 2010; Gupta and Lord, 1998; Karrh, 1998; Chang et al, 2009) as television companies seek new revenue streams to supplement declining advertising revenue, movie studios and computer games makers demand verisimilitude in TV drama, and brand marketing organisations look for greater reach and consumer engagement from their brand communications programmes (Lehu, 2007; Karrh et al, 2003). From a brand management perspective, product placement is conventionally used in integrated campaigns to increase brand awareness and to have a positive impact on consumer brand preference and purchase intention (Nelson, 2002; d'Astous and Chartier, 2000). It is also thought to reinforce consumer brand awareness and brand loyalty (Nozar, 2001) via trademark and logo exposure in dramatic entertainment.

Research studies have explored various definitions of product placement to capture the 'hybrid' character of the practice (Smit et al, 2009; Balasubramanian, 1994) in terms of its commonalities with sponsorship, advertising, publicity and celebrity endorsement (Baker and Crawford, 1995: Pardun and McKee, 1999). Other studies have categorized product placement practices in terms of, for example, implicit or explicit placement (d'Astous and Seguin, 1999) or the location of brand references in scene, plot or script (Russell, 1998; see also Shapiro, 1993; and Wenner, 2004). The focus on brand rather than product has led some researchers to suggest that the term 'brand placement' is more appropriate (Karrh, 1998; Babin and Carder, 1996; Morton and Friedman, 2002) while others have used the broader term 'entertainment marketing' to stand for all forms of branded content (Lehu, 2007; Hackley and Tiwsakul, 2007). The term 'product placement' remains in common usage in both industry and academic literature.

Many definitions of product placement (e.g. those of Balasubramanian, 1994; Ford, 1993; Karrh, 1998) have a limitation in that they do not account for the different media contexts and regulatory environments in different countries. For example, some focus on movies and television shows (e.g. Gupta and Gould, 1997) although it is also common to see brands placed in computer games, books, stage plays and popular music (e.g. Delattre and Colovic, 2009). Moreover, most extant definitions emphasise that placements are 'paid for' by the advertiser but this ignores two important issues. One is that many media vehicles use brands as scene props or scripted references for dramatic realism. TV producers and directors need brands to make dramas appear realistic to viewers, hence the benefit is two-way. The other is that, even in well-developed TV product placement markets such as the USA, some 4 out of 
5 brands appearing on TV are not paid for, yet may still yield benefits for the manufacturer (Hackley and Hackley, in press). In the UK, for example, the majority of brands appearing on $\mathrm{TV}$, even on the non-commercial BBC, are there through the free prop supply system. The brand manufacturer pays nothing, and the TV studio receives nothing. Consequently, defining product placements only in terms of 'paid for' and contracted placements ignores the majority of placement incidents.

These 'serendipitous' placements (Chang et al, 2009) that are not paid for or contracted are there because of the needs of the producer for dramatic verisimilitude. They need a mobile phone, or a can of beer, or a car, and they source the easiest or nearest item. In many countries, there are thousands of hours domestic TV programming produced per year, and it is not possible to make contracts for every incident of brand appearance. It must be acknowledged also that the high number of non-contracted brand appearances in TV shows does present a potential risk to brand owners and has resulted in the phenomenon of 'product displacement' where brand owners insist that TV producers obscure brand logos. Leaving aside for the moment the risks that unplanned media exposure might result in negative publicity for a brand, it is clear that payment is not a necessary condition for brand placement to take place. In the UK, for example, well-established product placement agencies place their clients' brands with television, movie or computer games manufacturers as 'free' props, taking a fee from the client for so doing. The media vehicle using the brand may pay nothing, but this does not mean that the exposure was not sought, paid for, and potentially very beneficial to, the brand.

Leading UK product placement agency the New Media Group (NMG) define product placement as "the technique by which brand name products, packages, signs, services and corporate names are intentionally positioned in feature films, television programmes and computer games" (NMG, 2005). Placements that are not paid for may nonetheless be present as a result of negotiation between the product placement agency and the studio prop buyers. In Thailand, product placements are not usually negotiated by a specialist agency but by the media arm of advertising agencies. In many cases these are separately negotiated and paid-for arrangements, but in many other cases they are unpaid add-ons negotiated to add value to the spot advertising. The common research definition of product as 'paid for' therefore ignores the largest category of placements, those that are there apparently serendipitously but within a tacit framework of negotiation and supply.

The scope of product placement research to date has generally focused on movies rather than other media vehicles, typically in a US national context (Tiwsakul et al, 2005) although there is a recent movement in Europe toward more research into placements in TV and other media (e.g. Smit et al, 2009; van Reijmersdal, 2010). Many quantitative studies have revealed generally positive consumer attitudes toward product placement, but there is a relative shortage of managerial studies which ask how the practice might be best managed (see Gupta et al, 2000; Russell and Belch, 2005, for exceptions). A need for more research has been highlighted to elucidate product placement management practices, strategies and consumer responses in different cultural contexts and from new theoretical perspectives (Hackley and Tiwsakul, 2006). 


\section{Background: The Media Environment in Thailand and the UK}

In Thailand, although economic development is very uneven, television access is high with more than $80 \%$ of Thai households owning a television set (Siriyuvasak, 2001). Thailand has 6 national terrestrial television channels, some of which are informative rather than commercial. There is wide access to most international subscription channels. Thailand has an advanced media and advertising industry catering for a vibrant consumer culture, especially in the major urban centres. Television advertising expenditure is substantial (Punyapiroje et al, 2002), taking the largest share of an overall adspend of some 73 billion Thai baht in 2005 according to AC Neilson Media Research Thailand. Standards of production and creativity are high in Thai advertising and television production, and Thai advertising in particular is known for its creativity, humour and visually spectacular (Sherer, 1995). Product placement is well-established as an industry in Thailand and a common part of promotional campaigns.

In the UK, most citizens have access to a TV set. There is one non-commercial broadcaster, the BBC, and one commercial television network, the ITV group, consisting of five terrestrial broadcasters, and numerous commercial cable and satellite channels. The UK is known for its advanced media production and infrastructure but, as we note above, there is only a very recent and limited tradition of 'paid for' product placement. Nonetheless, placements are common as 'free prop supply', while syndicated international shows shown on UK TV carry numerous placements, for which the UK channels receive no payment. In the UK, Ofcom, the Office of Communication, is the main media regulator monitoring the voluntary compliance with its codes of practice. In Thailand, there is no code of practice for product placement specifically but, rather, a code of media practice which includes restrictions on television exposure for certain categories of product such as weapons, alcohol and tobacco. The Thai authorities (primarily the Food and Drug Administration or FDA) rule on whether placement or sponsorship agreements are permissible on a case-by-case basis.

The respective media cultures have some commonality. In each country, soap operas, syndicated US shows and international movies shown on terrestrial and subscription TV are very popular. UK advertising is known for its 'soft sell' approach, high standards of creativity and production and use of humour. Thai advertising, similarly, is also known for its humour and high production standards as well as the pre-eminence of emotion and relationships as creative themes (Punyapiroje, 2002). Owning Western brands has been considered a mark of prestige in Thailand since

the period of King Rama IV (1851-1868) and King Rama V (1868-1910), when Western technologies and knowledge first came to Thailand and Western brands were associated with wealth, power and prestige (The Office of the Prime Minister, 1991; Tirakhunkovit, 1980). International products often appear in locally produced Thai TV shows, as they do in the UK.

\section{Method}

In this study a secondary review of product placement practice and research was undertaken, followed by a review of the respective media environments in the UK and Thailand. Tapes were recorded of product placement incidents on UK and Thai TV, in order to gain a general understanding of the kinds of placement practices which are preeminent. Following this, leading agency practitioners were identified in each country and interviewed. Sampling proceeded on a purposive basis (Lincoln and Guba, 1985). The main criterion was whether the participants had suitable seniority and experience to answer the key questions of the 
study. Those practitioners agreeing to be interviewed included senior practitioners from the top two ranked UK product placement agencies, and from the Bangkok branches of three leading advertising agency groups. Interviews of up to one hour with ten leading practitioners were conducted on the practitioners' premises. Interviews were conducted in English, with translation assistance where necessary from the bi-lingual first author, and fully transcribed. Transcriptions were coded and re-analysed to generate key themes, drawing on influences from interpretive qualitative research (Thompson et al, 1994, 1989; Spiggle, 1994; Hirschman and Holbrook, 1992; Miles and Huberman, 1994: Belk et al, 1988) and framed by a contextual understanding of the surrounding culture and environment. Previous findings from the research have focused on consumer cultural issues (e.g. Tiwsakul and Hackley, 2009) while the present paper focuses on managerial issues. Developments in practice and regulation in the years since the data were gathered have been incorporated into the analysis.

\section{Findings}

\section{Accounts of Product Placement Practice}

In Thai, the phrase 'product placement' cannot be directly translated. The phrase 'kod-sa-nafaeng', however, is widely understood. It translates as 'implicit advertising', which suggests the nature of this practice in Thailand, that is, it is mostly in the commercial interest. On Thai television, product placement and sponsorship are regarded dimensions of the same broad category of promotion. The phrase 'sa-nub-sa-nun-deow' is used when television programmes are sponsored by particular brands. In Thai game shows and talk shows, presenters might announce the names of the sponsors during the shows and there could be some visual placements of logos or products. The sponsors' names are also shown in the credits at the end of the programmes. Similarly, in Thai soap operas and sitcoms, brands placed in the shows are also named in the credits at the end of the show.

In UK television, a small P logo appears briefly in the corner of the screen to announce that paid-for placements are included in the show. Unpaid, serendipitous placements or those supplied by 'free props' agencies are not announced. Under Ofcom regulations there are strict limits on how a brand may appear: it cannot be unduly prominent, and it must be editorially justified. Sponsored television programmes in the UK are not allowed to prominently feature the sponsor's brands, although under the new regulations it is now possible for sponsored shows to feature placed brands. Sponsorships are announced with an 'ident' or other form of announcement at the beginning, end and in each commercial break. No paid for placements are allowed in news, documentaries or children's programming, and there are bans on paid for placements for alcohol, cigarettes, drugs and guns. The BBC is not allowed to engage in any revenue-earning promotional activities whatsoever.

In Thailand, in contrast, a TV show can, within the general guidelines on placements of particular product categories, negotiate any degree of brand exposure with a brand owner without having to make an explicit announcement about a sponsorship arrangement. It is common for TV presenters in certain genres of Thai TV show to mention brands, as in "Thank you to XXX for supplying these wonderful clothes". This would not normally happen in reality shows, since they are not usually scripted. There is a genre of TV show in Thai TV which is effectively a brand vehicle in which the brand is not explicitly mentioned but is placed prominently throughout. In such a show the brand might or might not be mentioned in the script, but it would be listed in the credits at the end of the show. 
So, both the language and the concept of product placement differ in the UK and Thai TV industries. The Thai concept covers a broader range of brand exposure in TV since the rules on explicit announcements about brand arrangements with TV programming are less stringent than in the UK. Therefore, the categories product placement and sponsorship merge in Thai TV, while in the UK they are distinct.

\section{Product Placement Industry Actors}

The actors involved in the product placement process are identified from the accounts of practitioner research participants. In each country the main actors involved in the process include account handlers from advertising, product placement or media agencies: brand client representatives; television executives, studio officials and prop buyers. 'Invisible actors' included regulators, clients, and consumers/viewers.

The present study does not include interviews with brand clients. One reason is pragmaticthey will not generally discuss their product placement strategies and do not normally reveal the contractual arrangements undertaken in product placement deals. This was confirmed by several agency-based respondents. A second is that clients tend to be at arms length in the process. Some clients, as noted below, simply are not aware of product placement strategies and leave it to the intermediaries to get that kind of exposure if they can. Product placement is treated as an 'add-on' to leverage a higher order of brand recognition from the advertising. Other, more sophisticated clients, particularly the major global brand marketing organizations, have in-depth knowledge of placement strategies with regard to their own brands but do not normally negotiate or design placements themselves but through the agencies.

In the UK, product placement campaigns are created by media and specialist product placement agencies, whereas in Thailand product placement services are provided by general advertising and media agencies. At the time of writing, we are not aware of any specialist product placement agency in Thailand. As N., a Strategy Director at a leading international media agency located in Bangkok, Thailand commented: "[There is] no specialist. It's not on its own right. It's an extension of the media buying agencies, part of media buying."

Specialist product placement agencies are increasingly well-established in the UK. As noted, such agencies in the UK gather fees from clients for placing the brand with the studio. They maintain some control over the context through their informal contacts with studio personnel including prop buyers, producers and script writers. Respondents claimed that in Thailand, most product placements on Thai TV are paid for, though there is no way to verify this claim. Contracts are confidential and there are no public data available. In contrast, in the UK most legitimate television product placements are assumed to be unpaid, under the 'free prop supply' system. UK product placement agencies can quantify the amount of exposure the placed brand gets through their 'free prop supply' arrangement by using software which scours TV programming and adds up the number of exposures each brand gets in nonadvertising programming. These data are used to show that brands that are clients of the placement agencies get substantially more airtime exposure than non-client brands. Since 2011 a parallel paid-for market has emerged, although the rules governing paid for placements are so stringent that the market remains very small (Hackley and Hackley, in press). 


\section{Fee Structures in Television Product Placement}

According to most advertising and media professionals interviewed, product placement services provided to clients could be classified into two main categories; implicit and explicit product placement. One leading UK product placement specialist categorised three main types: television, film and tactical (e.g. game shows and makeover programmes). These distinctions did not seem to fit into set fee categories in Thai TV placements. A Strategy Director at a Thai media agency revealed that "We don't have a set price for product placement and we negotiate as hard as we can to try to get it for free but the reality is we have to pay." Other respondents implied that sometimes it is possible to get free placements when the agency can use the leverage of a large spot advertising contract.

It is well known that some product placement deals operate on a barter agreement, where, for example, cars are provided as scene props for a movie free of cost to the producers. In general, the Thai situation seemed to be that the price for each deal is negotiable separately, though there are probably implicit norms known within the industry. In the UK the situation is different as we have noted. For roughly $£ 30-£ 60,000$ per year a brand client can get up to sixty seconds of aggregated TV exposure through the 'free prop supply' system, but may be asked for far more than that for just one, ten second 'paid-for' and contracted deal. The advantage of the paid-for deal is that it is guaranteed, but the volume of programme making so far exceeds the capacity of the industry to negotiate paid for deals that clients working through free prop supply are seldom disappointed. There are about 12 major product placement agencies in the UK dealing in free prop supply, and many of these are also involved in negotiating paid-for deals. The fee for a free prop supply deal covers establishing target audiences and appropriate strategy; vetting and script analysis; creative and design guidance; ordering and 'personal shopping' (organising logistics); 'damage control'; and reports including quarterly updates.

\section{Product Placement Strategy}

Brands in UK television are there primarily to enhance the verisimilitude of scenes, at the discretion of directors. In general, success is equated to exposure without regard for the relevance or impact of the precise context. UK agency practitioners may be able to choose the media vehicles in which clients' brands appear through their industry contacts. As one UK practitioner argued, "We confirm which television programmes we feel are pertinent to each brand". However, the way the brand might be used in the show cannot be guaranteed. The UK practitioner went on, "...the key is to keep in touch with those prop buyers...communicate with them what you're doing and of course you will be there first... [they] make decisions on which brands are actually in sets... so that's an advantage we have over those product placement, so called product placement companies that are part of a media agency or part of an ad agency or part of PR."

Links with studio personnel are clearly important in both countries: a TV Director of an international media agency in Bangkok had a "good link" with all TV producers, TV channels and prop buyers. Generally, in Thailand, in spite of the absence of specialist agencies, the process seemed more precise and strategic than in the UK. A Thai-based Media Strategy Director explained the process involved in generating a product placement for a client: "The target audiences are matched up, the environment is correct and we can talk to the programme producers and they agree to allow product placement ... and from that we go ahead with the placement." He added, "We sign a contract...to say this is what would like to 
happen....We have some control and they have to do [placements] for us because we pay." This agency provides a guideline to the production team stating, for instance, which scenes its clients' products should be seen or used in, and whether in the background or explicitly used by main characters. Even in Thailand, though, agencies do not have full editorial control over the programme content and clients have to accept a degree of risk.

\section{Product Placement Effectiveness}

In both countries, practitioners agreed that television product placement worked best as a "soft sell", although what is regarded as soft sell in Thailand may be very different to the UK. Most advertising and media practitioners in Thailand referred to it several times during their interviews. In the UK, this soft sell element was taken-for-granted since the brand is seen as merely a scene prop. In Thailand and the UK some practitioners complained that clients held a naïve view, wanting their brand to be featured as prominently as possible without regard to editorial context. In some cases this kind of prominent placement seemed to be possible on Thai TV, with, for example, lingering tight-focus close-up shots of hotel brands, phones or wrist watches in daytime soap operas. But industry professionals were keen to emphasise that the strength of placement was in a 'soft sell' approach. This could mean no explicit mention but might include highly prominent brand visibility.

As one Thai practitioner noted, "We have to be careful that we're not doing too much hard sell because it doesn't look good for our clients...placements should not be too commercialised". Placements were seen as ways to 'reinforce the brands' or 'add value' as part of an overall 'brand platform'. One Thai practitioner argued that, "Due to media and audience fragmentation, placing brands in television programmes could be seen as an evolution of a different way to reach consumers...It looks natural and could be viewed as an art". Another added that "People are sensible enough. They're smart enough to know when they've been sold to and if they know that advertising is tricky, that might turn them off ... I think they understand if they watch commercial TV, they're going to see commercial messages. If those come through in the way of product placement ...it may be beneficial, they will go haha that's quite clever. That may make them feel more positive towards the brands. If we get it wrong and the consumers look at it and go urgh, don't sell it to me, then it's ineffective." This was raised as a key issue by Thai practitioners. Thai consumers, too, tire of crudely designed placements and much prefer subtlety (Tiwsakul and Hackley, 2009). The agency practitioners know that if the audience objects to their favourite show being dominated by brand placements it will mean less benefit for the client in the long term. Clients, for their part, know that recall scores are higher for prominent and incongruous placements. However, there is no indication that recall translates to positive brand equity.

Evaluation of placements is sophisticated in each country. According to a Thai Account Management Director, it was not only the placements themselves that should be evaluated, but also overall communications of the brands. Clients would use sales figures, retail and audit data along with measures of consumer attitudes and TV show audience figures. In the UK, the more sophisticated specialist placement agencies used exposure tracking software which monitored all TV programmes for brand appearances, evaluating each exposure by size of the audience, quality (from 'wallpaper' to in-hand or consumption), and length and timing of the placement. Important variables include $\mathrm{CPH}$ (cost per hundred consumers reached), TVR (television rating) and 'Daypart', (whether it broadcasts in daytime, early peak, late peak or late night). 


\section{Discussion}

This research has begun to address a significant research gap concerning differences of practice and strategy in television product placement in Asia and The West. While previous researchers have studies the managerial perspective in the US (Russell and Belch, 2005) with some applicability to product placement strategy elsewhere, there are few studies which focus on comparative practice in cross-cultural contexts. The UK and Thailand represent interesting contrasts for comparison, since the UK is a relatively under-developed and heavily regulated environment for television product placement while Thailand has a mature though relatively un-regulated product placement industry. The sample of respondents was relatively small but they were all senior practitioners with a wealth of expertise and long experience of this field in their respective countries and beyond. The sample was purposive and the participants' views authoritative, in-keeping with the topic of inquiry (Lincoln and Guba, 1995).

Previous research has generated many insights about product placement, largely from an audience perspective, and typically focusing on Western cultural contexts (overview in Lehu, 2007). In a consumer-focused study, Tiwsakul and Hackley (2006) found that Thai consumers were acutely aware of and engaged with product placement on their favourite television shows. The regularity of viewing weekly or daily soap operas and news shows, and the intimate quasi-relationship between television consumers and their favourite stars, made television a particularly resonant medium for product placement (Tiwsakul and Hackley, 2009). Practitioners in each country were well aware of the power brands in TV shows hold for TV viewing consumers as a means of elaborating on the brand meaning, reinforcing the consciousness of brands and adding prestige through usage by much-loved TV characters and actors. Television is an especially influential medium since it locates brands within dramatic scenarios with which consumers closely identify and valorize (Peñaloza, 2001; Russell, 2002; Chang and Roth, 2000; Russell and Stern, 2006). What is more, the increasing international mobility of young, affluent consumers means that they are faced with a challenge in negotiating their sense of identity across two or more cultures (Tiwsakul and Hackley, 2012). Television programmes offer a fitting resource for this task given their international availability.

From the present study it was apparent that, while there are some commonalities of practice between the UK and Thailand, significant local knowledge is clearly required for the effective international management of brand communications. For example, in Thailand the client can negotiate considerable creative control over how the brand will be portrayed in the TV show. The danger of this is that client's economic power can distort the dramatic integrity of TV shows by pushing for contrived and incongruous placements, which tend to be resisted by viewers (Tiwsakul and Hackley, 2006). Indeed, editorial integrity, along with consumer ethics, are primary concerns of the UK Government media regulator Ofcom in designing the product placement code of practice (Hackley et al, 2008). One lesson to be learned from television product placement in Thailand is that if clients are allowed to dictate editorial content through their economic power, they will do so, even though agency practitioners are convinced that subtle placements are best for brand equity in the long term. Increasingly, successful TV shows are seen as media brands in their own right, and it would seem wise to manage product placements for the mutual benefit of TV show and brand client. A show that is known to be merely a promotional vehicle has limited source credibility as a vehicle for brands. 
International promotion strategy incorporating television product placement needs to be informed by knowledge of the very different industry infrastructure that obtains internationally. For example, there are no specialist product placement agencies in Thailand so clients have to deal with media and advertising agencies in order to access the necessary contacts and expertise. In the UK, product placement can be conducted through specialist agencies dealing in free prop supply, or through major TV channels that have created their own product placement sales teams since the new regulations allowing paid-for placements came into force. The costs of product placement through free prop supply are relatively low in the UK, but there is little control possible over the context of placement because there is no contract with the TV studio. The cost of contracted, paid-for placements is currently prohibitively high, but as the market develops this may change. In Thailand, unlike the UK, clients can negotiate detailed contracts directly with programme executives to specify the nature and timing of the brand exposure to a high degree. Furthermore, clients can sponsor TV shows which will discuss, feature and often demonstrate the client's product or service within the show. This is not possible in the UK because of the strict regulations separating editorial and sponsorship from advertising. In addition, in the UK there are strict rules about the prominence of placements. In Thai television the limits of exposure are decided by the programme makers. In both countries there are limits on the categories of product or service which can receive exposure in television, weapons, drugs and alcohol being the most obvious examples.

In Thailand, the measurement of placement effectiveness is sophisticated and parallels advertising effectiveness measures, with placements being evaluated by ROI. The UK situation is likely to change radically over the next five years as paid-for placements increase on commercial UK TV, but the product placement agencies already have a relatively well developed system for measuring the quantity and quality of brand exposure. The longer establishment of the industry in Thailand means that more complex measurement processes are in place for assessing the value of exposures. Evaluation of placement effectiveness remains complex, and depends on the marketing problem the exposure was designed to solve, whether that was concerned with positioning, sales generation, long term brand equity, competitive activity, market share or any other marketing objective. Overall, there is an industry consensus that brand/product placements on TV generate such high visibility and prestige that benefits accrue in the form of enhanced brand equity and wider audience reach, but the long term sales affects are far more difficult to calculate with precision.

\section{Concluding Comments}

This study has addressed a gap in previous research by conducting a managerial investigation into product placement as an aspect of promotional strategy in Thailand and the UK. Both countries offer many opportunities for brands to be placed in television and therefore could form part of a co-ordinated international promotional campaign. However, the local conditions under which brands may receive exposure in television programming are very different as regards the principal actors, fee structures, media infrastructure and regulatory systems. The study has illustrated why local knowledge is essential for brand clients intending to use television programme exposure in their international promotional strategy, but it has also suggested that there is enough commonality for campaigns spanning Asia and the West to be worthwhile. In addition, the study suggests that further research is needed into 
product placement strategy in local television contexts to detail differences in media regulation and agency practice.

\section{Reference}

Babin, L. A., and Carder, T.S. (1996), Viewers' recognition of brands placed within a film, International Journal of Advertising, Vol. 15, Iss. 2, p. 140-151.

Balasubramanian, S. K. (1994), Beyond advertising and publicity: hybrid messages and public policy issues, Journal of Advertising, Vol. 23, Iss. 4, p. 29-47.

Belk, R. W., Sherry, J., F. and Wallendorf, M. (1988) 'A naturalistic enquiry into buyer and seller behaviour at a swap meet', Journal of Consumer Research, 14, 4: (March): pp.449-70.

Chang, S., Newell, J. and Salmon, C.T. (2009) Product Placement in Entertainment Media: Proposing Business Process Models, International Journal of Advertising, 28(5) pp. 783-806.

Chang, J. E. and Roth, E. W. (2000), "When is cranberry sauce shaped like a can? An investigation of cultural capital, gender and consumption in television programming", Schroeder, J. E., and Otnes, C. (eds.), Association of Consumer Research on Gender, Marketing, and Consumer Behaviour, Urbana, University of Illinois, p. 107-123.

d'Astous, A., and Seguin, N. (1999), Consumer reactions to product placement strategies in television sponsorship, European Journal of Marketing, Vol. 33, Iss. 9/10, p. 896910.

Delattre, E. and Colovic, A. (2009) Memory and Perception of Brand Mentions and Placements of Brands in Songs, International Journal of Advertising, 28(5) pp. 807842.

Gupta, P. B., and Gould, S. J. (1997), Consumers' perceptions of the ethics and acceptability of product placements in movies: Product category and individual differences, Journal of Current Issues and Research in Advertising, Vol. 19, Iss. 1, p. 37-50.

Gupta, P., B., and Lord, K. R. (1998), Product placement in movies: The effect of prominence and mode on audience recall, Journal of Current Issues and Research in Advertising, Vol. 20, Iss. 1, p. 47-59.

Ford, B., and Ford, J. (1993), Television and sponsorship, Oxford: Butterworth-Heinemann.

Gupta, P. B., Balasubramanian, S. K., and Klassen, M. (2000), "Viewers' evaluations of product placements in movies, public policy issues and managerial implications", Journal of Current Issues and Research in Advertising, Vol. 22, Iss. 2, p. 41-52.

Hackley, R. A., and Hackley, C. (in press) Unpaid product Placement: The Elephant in the Room in the UK's New Paid-For Product Placement Market, International Journal of Advertising 
Hackley, C., and Tiwsakul, R. (2006), Entertainment marketing and experiential consumption, Journal of Marketing Communications, Vol. 12, Iss. 1, p. 63-75.

Hackley, C., Tiwsakul, R. and Preuss, L. (2008) An Ethical Evaluation of Product PlacementA Deceptive Practice?' (2008) Business Ethics- A European Review Vol 17, No 2 (April) pp.109-120.

Hirschman, E. C., and Holbrook, M. B. (1992), Postmodern consumer research: The study of consumption as text, Newbury Park, CA: Sage.

Hudson, S. and Hudson, D. (2006) Branded Entertainment: A New Advertising Technique or Product Placement in Disguise? Journal of Marketing Management, 22 5/6 pp. 489504.

Karrh, J. A. (1998), Brand placement: A review, Journal of Current Issues and Research in Advertising, Vol. 20, Iss. 2, p. 31-49.

Karrh, J., McKee, K.B. and Pardun (2003) Practitioners' Evolving Views on Product Placement Effectiveness, Journal of Advertising Research, June, 43(2) pp.138-149.

Lehu, J-M (2007) Branded Entertainment: Product Placement and Brand Strategy in the Entertainment Business, Kogan Page, London and Philadelphia.

Lincoln, Y. S., and Guba, E. G. (1985), Naturalistic inquiry, Beverly Hills, CA: Sage.

Miles, M. B., and Huberman, M. A. (1994), An Expanded sourcebook: qualitative data analysis, London: Sage

Mortan, C., and Friedman, M. (2002), "I saw it in the movies": Exploring the link between product placement beliefs and reported usage behaviour, Journal of Current Issues and Research in Advertising, Vol. 24, Iss. 2, p. 33-40.

Nelson, M. R. (2000), Recall of brand placements in computer/video games, Journal of Advertising Research, Vol. 42, Iss. 2, p. 80-93.

Nozar, R. A. (2001), Product placements help heighten brand exposure Hotel \& Motel Management, Vol. 216, Iss. 9, p. 3-4.

Pardun, C.J. and McKee, K.B. (2000) Product Placements as Public Relations: An Exploratory Study of the Role of the Public Relations Firm, Public Relations Review, 25(4) pp. 481-493.

Peñaloza, L. (2001), "Consuming the American West: animating cultural meaning and memory at a Stock Show and Rodeo", Journal of Consumer Research, Vol. 28, Iss. December, p. 369-398.

Punyapiroje, C., Morrison, M., and Hoy, M. (2002), A nation under the influence: The creative strategy process for advertising in Thailand, Journal of Current Issues and Research in Advertising, Vol. 24, Iss. 2, p. 51-65. 
Russell, C. A. (1998), Towards a framework of product placement: Theoretical propositions, Advances in Consumer Research, Vol. 25, Iss. p. 357-362.

Russell, C.A. and Belch, M. (2005) A Managerial Investigation into the Product Placement Industry, Journal of Advertising Research, 45, 73-92.

Russell, C. A. (2002), "Investigating the effectiveness of product placements in television shows: the role of modality and plot connection congruence on brand memory and attitude", Journal of Consumer Research, Vol. 29, Iss. 3, p. 306-319.

Russell, C. A. and Stern, B. B. (2006), "Consumers, characters and products: A balance model of sitcom product placement effects", Journal of Advertising, Vol. 35, Iss. 1, p. 7-21.

Siriyuvasak, U. (2003), Overview freedom of expression in Thailand, In: Goonasekera, A., and Chun Wah, L. (eds.), Asian communication handbook, Singapore: Asian Media Information and Communication Centre (AMIC) and School of Communication Studies, Nanyang Technological University.

Sherer, P. M. (1995), Selling the Sizzle: Thai advertising crackles with creativity as industry continues to grow, The Asian Wall Street Journal Weekly, 1, p. 6-7.

Smit, E., van Reijmersdal, E, and Neijens, P. (2009) Today's Practice of Brand Placement and the Industry Behind it, International Journal of Advertising, 28(5) pp.761-782.

Spiggle, S. (1994), "Analysis and interpretation of qualitative data in consumer research", Journal of Consumer Research, Vol. 21, Iss. p. 491-503.

Tirakhunkovit, V. (1980), Why Thais do not like Thai products? (in Thai), In: Monthly Business Journal, Bangkok, Thailand: Thailand Thurakij, p. 22-29.

Tiwsakul, R. and Hackley, C. (2012) Postmodern Paradoxes in Thai-Asian Consumer Identity' Journal of Business Research_Vol 66/4 490-496 http://www.sciencedirect.com/science/article/pii/S0148296311000609

Tiwsakul, R., Hackley, C., and Szmigin, I. (2005), Explicit, non-integrated product placement in British television programmes, International Journal of Advertising, Vol. 24, Iss. 1, p. $95-111$.

Tiwsakul, R. and Hackley, C. (2006) Young Thai and UK Consumers' Experiences of Television Product Placement- Engagement, Resistance and Objectification', in Craig-Lees, M., Gregory, G. and Davis, T. (Eds) (2006) Borderless Consumption: Asia Pacific Advances in Consumer Research Volume 7, pp. 371-376. 
Tiwsakul, R. and Hackley, C. (2009) The Meanings of 'Kod-sa-na-faeng'- Young Adults' Experiences of Television Product Placement in the UK and Thailand', (2009) Advances in Consumer Research, Vol. 36 Eds. Ann L. McGill and Sharon Shavitt, Duluth, MN : Association for Consumer Research, Pages: 584-586. Thompson, C. J., Pollio, H. R., and Locander, W. B. (1994), "The spoken and the unspoken: a hermeneutic approach to understanding the cultural viewpoints that underlie consumers' expressed meanings", Journal of Consumer Research, Vol. 21, Iss. December, p. 431-453.

Thompson, C. Locander, W. and Pollio, H. (1989), "Putting consumer experience back into consumer research: the philosophy and method of existential phenomenology", Journal of Consumer Research, Vol. 17, Iss. p. 133-147.

van Reijmersdal, E., Smit, E. And Neijens, P. (2010) How media factors affect audience responses to brand placement, International Journal of Advertising, 29(2) pp. 279302.

Wenner, L. A. (2004), On the ethics of product placement in media entertainment, Journal of Promotion Management, Vol. 10, Iss. 1/2, p. 101-132. 